\title{
Evaluation of oxidant and anti-oxidant balance in Behcet's disease and its correlation with disease activity
}

\author{
Vahid Yahyavi Alvar ${ }^{1}$, Seyyedeh Zahra Mirfeizi ${ }^{1 *}$, Mohammad Hasan Jokar ${ }^{2}$, Nafiseh Abdolahi ${ }^{3}$, Saeed \\ Kerdari $^{1}$ \\ ${ }^{1}$ Rheumatic Diseases Research Center, School of Medicine, Mashhad University of Medical Sciences, Mashhad, Iran; ${ }^{2}$ Departments \\ of Rheumatology, School of Medicine, Mashhad University of Medical Sciences, Mashhad, Iran; ${ }^{3}$ Bone, Joint and Connective Tissue \\ Research Center, Golestan University of Medical Sciences, Gorgan, Iran
}

\begin{abstract}
Behcet's disease (BD) is a multi-system, progressive disease which usually presents with oral aphthous and genital ulcers. It may involve other organs such as the eyes, joints, nervous and vascular systems. Although the origin of BD is unknown, it is proposed that immunological, viral, and toxic factors are responsible. The current study evaluated the oxidant/antioxidant balance (redox index) in Behcet's disease and its correlation with disease activity. Thirty BD patients were enrolled in the study based on International Study Group (ISG 1992) criteria. An age- and gender-matched control group was selected from healthy hospital staff. In this study, 3, 3, 5, 5 tetramethylbenzene (TMB) was used to determine oxidant/antioxidant balance. In the first enzymatic reaction, TBM was oxidized to a colorful cation. In the second chemical reaction, the colorful cation was regenerated to a colorless substance. In such way, the redox index was achieved. The redox index was significantly higher in the BD group than in the healthy group $(P=0.0140)$. The mean redox index varied significantly in different levels of disease activity and was higher in patients with a severe case in comparison with those with a moderate form $(P=0.038)$. There was a positive correlation between disease activity and redox index $(\mathrm{r}=0.450 ; P=0.013)$. A positive correlation was observed between the redox index and the WBC count in patients $(P=0.033)$. The findings of this study demonstrate the presence of oxidative stress in $\mathrm{BD}$, and the severity of $\mathrm{BD}$ has a moderately positive correlation with the redox index.
\end{abstract}

Keywords: Behcet's disease, disease activity, oxidant/anti-oxidant balance.

\section{Introduction}

Behcet's disease (BD) is a multi-systemic disorder. It was described by Hulusi Behçet in 1937 [1]. This progressive disease presents with oral aphthous and genital ulcers; it can involve the eyes, joints, nervous and vascular systems [2] and may lead to blindness or other disabilities [3]. Disease activity is measured by the severity of clinical manifestations; one assessment method is the BDCAF (Behcet's Disease Current Activity Form, 2006) [4]. In this study, BD performance in the last 28 days was evaluated [4]. BD is currently classified as a vasculitis [2] and is diagnosed based on clinical criteria; there is no pathognomonic laboratory test [3]. The origin of $\mathrm{BD}$ is unknown, but immune-based theories, viral and toxic factors have been proposed for its pathogenesis [5]. BD is a worldwide disorder, but it is most common in Asia and along the Mediterranean basin in countries like Iran, Turkey, and Iraq [5]. Its incidence varies between 13.5 and 370 cases in 100,000 people in different countries. Its prevalence in Iran is 1 in 6000, and 286 new cases are identified each year [6]. Some studies suggest that inflammation in BD is associated with cytokine release by $\mathrm{T}$ helper-1 [7]. High levels of circulating inflammatory mediators and interleukin-8 (IL-8) have been reported in many studies and correlate with uveitis presentation [8, 9]. Various proteins, such as heat shock proteins (HSPs), act as a cytoprotectant and an immunomodulator under stress conditions and in chronic diseases like Behcet's [10]. The efficacy of anti-tumor necrosis factor-alpha (TNF- $\alpha$ ) treatment in BD has been evidenced [11].

Erythrocyte sedimentation rate and C-reactive protein were used to determine the response to treatment in $\mathrm{BD}$ patients [12]. It is proposed that erythrocytes are more at risk of oxidative damage, because they are constantly exposed to oxygen. Some studies have shown that lipid peroxidation in erythrocytes was increased in BD patients [13]. Recently, the role of lipid peroxidation and oxygen free radical formation has been confirmed in many chronic

* Corresponding Authors: Seyyedeh Zahra Mirfeizi, E-mail: mirfeiziz@ mums.ac.ir, Tel: +98 51 38012753, Fax: +98 5138401036 Received: 03 September 2017; Accepted: 25 December 2017 
diseases, including rheumatoid arthritis, diabetes mellitus, and some connective tissue disorders [14]. Some studies have revealed that NO plays an important role in the pathogenesis of BD. There is some evidence of increased lipid peroxidation in BD. Oxidative damage was proposed as a probable pathogenesis of BD in 1982 [15]. Increases in reactive oxygen species (ROS) and reductions in antioxidant levels have been revealed by various studies [16]. Other studies have demonstrated that different functions of polymorphonuclear leukocytes are influenced in BD, such as chemotaxis, phagocytosis, lysosomal enzyme activity, and superoxide anion formation [2]. An impaired oxidant/anti-oxidant balance leads to tissue damage and self-injury [17]. The current study evaluated the oxidant/anti-oxidant balance in Behcet's disease and its correlation with disease activity.

\section{Materials and Methods}

This study was approved by the ethics committee of Mashhad University of Medical Sciences. Written consent was obtained from all participants, and the study was designed according to the tenets of the Declaration of Helsinki.

\section{Patient selection}

Based on previous studies, the sample size in this study was estimated using G-power software [18] to be about 29 cases in each group. Thirty BD patients were selected by convenience sampling and enrolled in this study based on International Study Group (ISG 1992) criteria [19]. Patients with co-morbid chronic diseases and individuals who had a recent history of antioxidant usage were excluded. The control group was selected from among healthy hospital staff members and was gender- and agematched with the case group.

\section{Clinical examination}

All patients were examined by the same rheumatologist. Diagnostic criteria proposed by ISG was used. The Behcet's Disease Current Activity Form 2006 (http://www.behcet.ws/pdf/BehcetsDiseaseActivityForm. pdf) was completed for each patient. This form assesses the 10 most common clinical features of $\mathrm{BD}$, which are headache, fatigue, oral and genital ulcers, pustules, superficial thrombophlebitis or erythema nodosum, arthritis and arthralgia, abdominal pain, dysentery, nausea and vomiting. Manifestations during the preceding 4 weeks were evaluated as an ordinal variable between 0 and 4 . Only ophthalmic lesions were scored between 1 and 3 . Total disease activity scores ranged from 0 to 43 with this method [20]. The physician's judgment is important in completing this scoring form and estimating the disease activity level.

\section{Oxidant/Anti-oxidant balance measurement}

In this study, the method proposed by Hamidi et al. [21] and the arbitrary unit of HK (Hamidi-Koliakos) were considered for the assessment of oxidant/anti-oxidant balance [22]. Briefly, venous blood samples were obtained from both groups $(5 \mathrm{cc})$. All blood samples were kept refrigerated at $-80^{\circ} \mathrm{C}$ after centrifuging. All assessments were performed in a single, equipped laboratory. To determine the oxidant/anti-oxidant balance, ' $3,3,5,5$, tetramethylbenzene (TMB) was used. In the first enzymatic reaction, TMB was oxidized to a colorful cation. In the second chemical reaction, the colorful cation was regenerated to a colorless substance. The redox index was achieved by measuring the cation concentration using absorption spectroscopy at $450 \mathrm{~nm}$ with a reference wavelength of 620 or $570 \mathrm{~nm}$.

\section{Statistical analysis}

Data was analyzed using Statistical Package for the Social Sciences for Windows (SPSS version 16). A p-value $<0.05$ was considered significant. The Independent $\mathrm{T}$ test was used to compare redox indices between groups, and Spearman's correlation coefficient was used to valuate the relationship between disease activity and the redox index. Moreover, univariate analysis or regression was used to determine how much BD activity is affected by clinical and laboratory factors.

\section{Results}

Sixty individuals (30 patients and 30 healthy subjects) were enrolled in this study. In both groups, 18 patients $(60 \%)$ were male and $12(40 \%)$ were female. Figure 1 shows the mean values of oxidant/anti-oxidant balance in patients and controls.

The redox index was significantly higher in $\mathrm{BD}$ patients than in the control group ( $169 \pm 43$ vs. $144 \pm 33, P=0.014)$. Demographic data and laboratory test findings from BD patients are summarized in Table 1.

The mean age of participants was $37.3 \pm 8.9$ years. Table 2 shows the characteristics of variables in 3 levels of Behcet's disease current activity (BDCA).

The redox index mean values varied significantly in different levels of disease activity; significantly higher values were seen in patients with severe cases of the disease compared with those with a moderate form $(P=0.038)$. WBC values were also higher in patients with the severe form of $\mathrm{BD}(P=0.016)$. Table 3 shows the correlation between clinical and laboratory factors and disease activity.

There was a positive correlation between BD activity Rheum. Res., Vol. 3, No. 3, Jul. 2018 
and redox index $(\mathrm{r}=0.399 ; P=0.029)$. A positive correlation was also observed between WBC and BDCA ( $\mathrm{r}=0.454$; $P=0.012$ ). Similarly, there was a moderately positive correlation between WBC and the redox index in this study
(Pearson Correlation $=0.391 ; P=0.033$ )

Table 4 shows the comparison of BDCA in men and women.

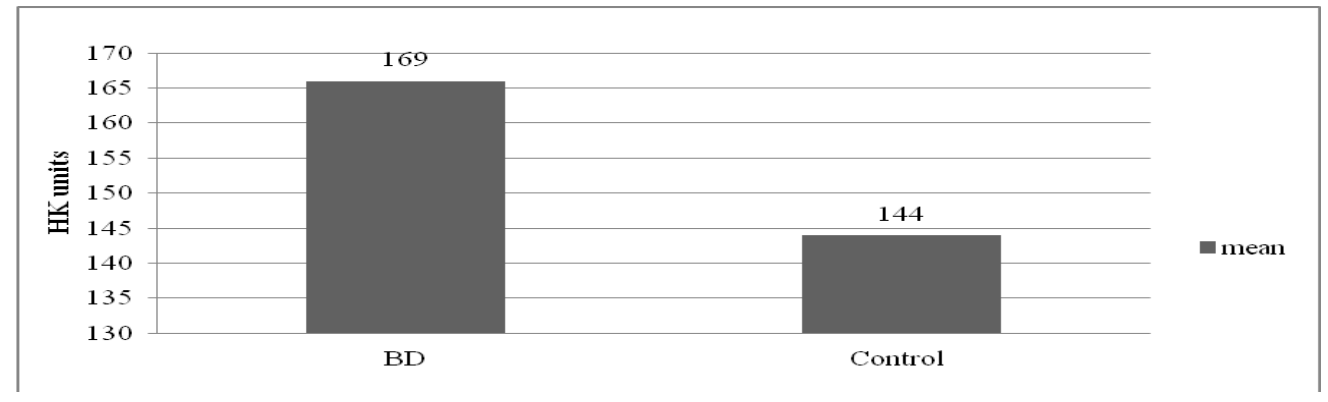

Fig. 1 The oxidant/ anti-oxidant balance in BD and control groups

Table 1. Characteristics of Variables in BD Group

\begin{tabular}{lc}
\hline & $\begin{array}{c}\text { Mean } \mathbf{\text { SD* }} \text { or N } \\
(\boldsymbol{\%})\end{array}$ \\
\hline Age(Years) & $37.33 \pm 8.95$ \\
WBC (Count per microliter) & $7916.67 \pm 1638.56$ \\
ESR(Millimeters per Hour) & $16.47 \pm 5.59$ \\
Balance (HK unite) & $169.82 \pm 43.65$ \\
CRP & \\
+1 & $28(93.3 \%)$ \\
+2 & $2(6.7 \%)$ \\
Sex & \\
Male & $18(60.0 \%)$ \\
Female & $12(40.0 \%)$ \\
Disease Activity (BDCA) & \\
Mild & $5(16.7 \%)$ \\
Moderate & $23(76.7 \%)$ \\
Sever & $2(6.7 \%)$ \\
\hline \multicolumn{2}{r}{ Standard deviation, Sample size $=30$}
\end{tabular}

Table 2. Comparison of characteristics of variables in three levels of disease activity (BDCA)

\begin{tabular}{|c|c|c|c|c|}
\hline & $\begin{array}{c}\text { Mild }(n=5) \\
\text { Mean } \pm \text { SD }^{*} \text { or } N(\%)\end{array}$ & $\begin{array}{c}\text { BDCA } \\
\text { Moderate }(\mathrm{n}=23) \\
\text { Mean } \pm \text { SD }^{*} \text { or } \mathbf{N}(\%)\end{array}$ & $\begin{array}{c}\text { Sever }(n=2) \\
\text { Mean } \pm \text { SD }^{*} \text { or } N(\%)\end{array}$ & $P$ value \\
\hline Age (yrs) & $34.00 \pm 8.75$ & $37.65 \pm 9.31$ & $42.00 \pm 2.83$ & $0.547^{* *}$ \\
\hline $\begin{array}{l}\text { WBC (Count/ } \\
\text { microliter) }\end{array}$ & $6820.00 \pm 1407.84^{\mathrm{a}}$ & $7921.74 \pm 1420.61^{\mathrm{a}}$ & $10600.00 \pm 2262.74$ & $0.016^{* *}$ \\
\hline $\operatorname{ESR}(\mathbf{m m} / \mathbf{h})$ & $13.60 \pm 2.88$ & $16.70 \pm 5.61$ & $21.00 \pm 9.90$ & $0.272^{* *}$ \\
\hline Balance (HK units) & $142.23 \pm 22.52^{\mathrm{a}}$ & $169.92 \pm 42.75^{\mathrm{a}}$ & $237.69 \pm 0.60$ & $0.027^{* *}$ \\
\hline
\end{tabular}

${ }^{*}$ Standard deviation, $* *$ ANOVA, ${ }^{\text {a }}$ No significant difference (by Duncan Post Hoc test in level 5\%)

Table 3. Relationship between BDCA and Other Variables

\begin{tabular}{lll}
\hline & rho* $^{*}$ & P-value \\
\hline Age & -0.106 & 0.575 \\
WBC & 0.452 & 0.012 \\
ESR & 0.262 & 0.162 \\
Balance & 0.399 & 0.029 \\
\hline
\end{tabular}

${ }^{*}$ Spearman correlation coefficient between BDCA and any variables
Table 4. BDCA is compared between men and women

\begin{tabular}{|c|c|c|c|c|}
\hline \multicolumn{5}{|c|}{ BDCA } \\
\hline & $\begin{array}{l}\text { Mild } \\
(\mathrm{n}=5)\end{array}$ & $\begin{array}{c}\text { Moderate } \\
(\mathbf{n}=\mathbf{2 3})\end{array}$ & $\begin{array}{l}\text { Sever } \\
(\mathbf{n}=2)\end{array}$ & \\
\hline Sex & & \multirow{3}{*}{$\begin{array}{l}13(56.5 \%) \\
10(43.5 \%)\end{array}$} & 2 & \multirow{3}{*}{$0.561^{*}$} \\
\hline Male & $3(60.0 \%)$ & & $(100.0 \%)$ & \\
\hline Female & $2(40.0 \%)$ & & $0(0.0 \%)$ & \\
\hline
\end{tabular}




\section{Discussion}

Behcet's disease is a chronic, inflammatory, relapsing syndrome. There is no accurate biochemical index to indicate disease activity, and laboratory tests such as erythrocyte sedimentation rate, leukocyte count, and Creactive protein are not specific [23]. The aim of the current study was to evaluate the oxidant/anti-oxidant balance (redox index) in Behcet's disease and its correlation with disease activity. In recent years, evidence for an antioxidant insufficiency in BD have been proposed. In the present study, the potential utility of an oxidant/antioxidant imbalance for monitoring $\mathrm{BD}$ activity was evaluated. Previous studies have concluded that regulation of the immune system is implicated in BD patients [7-11]. Increasing the levels of immune and inflammatory mediators, immunoglobulins, and free oxygen radicals supports the theory of an immunologic base for BD [1416]. A reduction in free radical scavenging enzymes (FRSEs) in BD leads to the insufficient removal of free radicals and results in tissue and DNA damage [24]. Findings in the current study confirmed a higher oxidant/anti-oxidant balance in patients with BD compared with healthy people.

The male/female ratio in the current study was 1:5. Other studies found the disease to be more frequent in women. This difference might be explained by the sample size and detailed selection criteria in this study. It has been shown that men present a more severe form of the disease [25] as was observed in the present study (Table 4).

As expected, BD patients had higher ESR and WBC levels and positive CRP compared with healthy individuals of similar age and gender.

Although ESR levels were higher in patients with the severe form of BD ( 16 vs. $21 ; P=0.330)$, the correlation between disease activity and ESR was not confirmed in the current study.

Ozuguz and Şahin showed that the ESR level increases in patients with active BD [26, 27]. Another study found a significant positive correlation between ESR level and disease activity [28]. The difference between the current findings and those of previous studies might have occurred because of variations in disease duration.

A study by Joung revealed that a severe clinical course of BD is associated with a younger age at diagnosis [29]. The current study findings, however, did not confirm this result, and the mean ages of various BD forms did not differ significantly between groups (mild form: 34 years; moderate form: 37 years; severe form: 42 years; $P=0.547$ ). This difference might be explained by the lack of patients who suffered from a more severe from of BD in the current study. Furthermore, no correlation between age, gender, and disease activity was found in this study.

The oxidant/anti-oxidant balance was higher in female patients than male ones in the present study, but this difference was not statistically significant (179 vs. 163; $P=0.321$ ). This finding may be explained by the higher prevalence of the more severe form of $\mathrm{BD}$ in women. Davatchi showed that only vascular lesions of BD are more common in males [7]. Tursen also concluded that multiorgan involvement is more common in male patients [30]. In the present study, the redox index was significantly higher in patients with a severe form of the disease, and a moderate correlation between BDCA and the redox index was observed.

Various oxidative markers are indicative of oxidative stress in BD. Bozkurt showed that total antioxidant status (TAS) decreased and the oxidative stress index (OSI) increased in BD patients in comparison with healthy controls [31]. Ozyazgan revealed that ischemia-modified albumin (IMA) and prooxidant-antioxidants balance (PAB) are two new markers of oxidative stress in BD. Nitric oxide (NO) is another parameter that is elevated in BD patients [32]. Harzallah showed a negative correlation between plasma malondialdehyde (MDA) and BD activity and duration [33].

The current study showed a positive correlation between WBC as an inflammatory marker and the redox index in patients with BD. This emphasizes the role of polymorphonuclear cell inflammatory activities in patients with BD as shown in previous studies, such as those by Shahneh, Kose, and Verity [8, 34, 35].

The current results revealed that the redox index can be used as a key marker for follow up in patients with BD and can identify the active phase of the disease. The oxidant/anti-oxidant balance measurement can be performed faster and is more accurate than nonspecific tests such as ESR and CRP.

The main limitation of the current study was that no cost effectiveness evaluation of redox index analysis compared with other oxidative parameters such as TAS was performed. Thus, further studies are needed to select the most reliable and accurate marker of oxidative stress in BD patients which is associated with disease activity and prognosis. Considering the oxidative status of patients with Behcet's disease can be helpful for selecting the optimal therapeutic approach.

In conclusion, the current findings demonstrate the presence of oxidative stress in $\mathrm{BD}$ and propose a correlation between the severity of $\mathrm{BD}$ and the oxidant/anti-oxidant balance. 


\section{Conflicts of interest}

The authors declare no conflict of interest.

\section{References}

1. Davatchi F, Shahram F, ChamsDavatchi C, Shams H, Nadji A, Akhlaghi M, et al. Behcet's disease in Iran: analysis of 6500 cases. Int J Rheum Dis 2010; 13(4): 367-73. doi: $10.1111 / \mathrm{j} .1756-185 \mathrm{x} .2010$ 01549. x.

2. Acikgoz N, Ermis N, Yagmur J, Cansel M, Karincaoglu Y, Atas H, et al. Elevated oxidative stress markers and its relationship with endothelial dysfunction in Behcet disease. Angiology 2011; 62(4): 296-300. doi: 10.1177/ 0003319710382417.

3. Vaya A, Rivera L, Todoli J, Hernandez JL, Laiz B, Ricart JM. Haematological, biochemical and inflammatory parameters in inactive Behcet's disease. Its association with red blood cell distribution width. Clin Hemorheol Microcirc 2014; 56(4): 319-24.

4. Isik A, Koca SS, Ustundag B, Selek S. Decreased total antioxidant response and increased oxidative stress in Behcet's disease. Tohoku J Exp Med 2007; 212(2): 133-41. doi: 10.1620/tjem.212.133.

5. Shi Y, Jia Y, Hou S, Fang J, Zhou Y, Kijlstra A, et al. Association of a TNIP1 polymorphism with Vogt-Koyanagi-Harada syndrome but not with ocular Behcet's disease in Han Chinese. PLoS One 2014; 9(5): e95573. doi: 10.1371/journal.pone.0095573.

6. Coskun B, Saral Y, Godekmerdan A, Erden I, Coskun N. Activation markers in Behcet's disease. Skinmed 2005; 4(5): 282-6. doi: 10.1111/j.1540-9740.2005.03865. $\mathrm{X}$.

7. Savey L, Resche-Rigon M Wechsler B, Comarmond C, Piette $\mathrm{JC}$, Cacoub P, et al. Ethnicity and association with disease manifestations and mortality in Behcet's disease. Orphanet J Rare Dis 2014; 9(1): 42. doi: 10.1186/1750-1172-9-42

8. Shahneh FZ, Babaloo Z, Baradaran B, Hamzavi F, Bayazi B, Bandehagh A. Behcet's syndrome in Iranian Azari people. Pak J Biol Sci 2012; 15(21):
1045-7. doi: 10.3923/pjbs.2012. 1045.1047

9. Durmazlar SP, Ulkar GB, Eskioglu F, Tatlican S, Mert A, Akgul A. Significance of serum interleukin-8 levels in patients with Behcet's disease: high levels may indicate vascular involvement. Int $J$ Dermatol 2009; 48(3): 259-64. doi: 10.1111/ j.1365-4632.2009.03905.x.

10. Sahebari M, Hashemzadeh K, Mahmoudi M, Saremi Z, Mirfeizi Z. Diagnostic Yield of Heat Shock Protein 70 (HSP-70) and AntiHSP-70 in Behcet-Induced Uveitis. Scandinavian Journal of Immunology 2013; 77(6): 476-81. doi: $10.1111 /$ sji.12045.

11. Furuta S, Chow YW, Chaudhry AN, Jayne D. Switching of antiTNF- $\alpha$ agents in Behçet's disease. Clin Exp Rheumatol 2012; 30(3 Suppl 72): S62-8.

12. Davatchi F, Shahram F, ChamsDavatchi C, Sadeghi Abdollahi B, Shams H, Nadji A, et al. Behcet's disease: is there a gender influence on clinical manifestations? Int J Rheum Dis 2012; 15(3): 306-14. doi: $\quad 10.1111 / \mathrm{j} .1756-185 x .2011$. 01696.x.

13. Djaballah-Ider F, Chaib $\mathrm{S}$, Belguendouz H, Talbi D, TouilBoukoffa C. T cells activation and interferon-gamma/nitric oxide production during Behcet disease: a study in Algerian patients. Ocul Immunol Inflamm 2012; 20(3): 215-7. doi: 10.3109/09273948. 2012.671882.

14. Najim RA, Sharquie KE, AbuRaghif AR. Oxidative stress in patients with Behcet's disease: I correlation with severity and clinical parameters. J Dermatol 2007; 34(5): 308-14. doi: 10.1111/j.1346-8138.2007.00278. $\mathrm{x}$.

15. Sezer ED, Aksu K, Caglayan O, Keser G, Karabulut G, Ercan G. DNA damage and its relationship with other oxidative stress parameters in Behcet's disease. Rheumatol Int 2012; 32(1): 217 22. doi: 10.1007/s00296-0101605-0.

16. Singer O. Cogan and Behcet syndromes. Rheum Dis Clin North Am 2015; 41(1): 75-91. doi: 10.1016/j.rdc.2014.09.007.

17. Hatemi G, Seyahi E, Fresko I, Talarico R, Hamuryudan V. Behcet's syndrome: a critical digest of the 2013-2014 literature. Clin Exp Rheumatol 2014; 32(4 Suppl 84): S112-22.

18. Taysi S, Demircan B, Akdeniz N, Atasoy M, Sari RA. Oxidant/antioxidant status in men with Behcet's disease. Clin Rheumatol 2007; 26(3): 418-22. doi: 10.1007/s10067-006-0513-x.

19. Wechsler B, Davatchi F, Mizushima Y, Hamza M, Dilsen $\mathrm{N}$, Kansu E et al. Evaluation of diagnostic ('classification') criteria in Behçet's disease-towards internationally agreed criteria. The International Study Group for Behçet's disease. Br J Rheumatol 1992; 31(5): 299-308. doi: 10.1093/rheumatology/31.5.299.

20. Gheita TA, Gamal SM, Shaker I, El Fishawy HS, El Sisi R, Shaker OG, Kenawy SA. Clinical significance of serum interleukin23 and $\mathrm{A} / \mathrm{G}$ gene (rs17375018) polymorphism in Behçets disease: Relation to neuro-Behçet, uveitis and diseaseactivity. Joint Bone Spine 2014; 82(3): 213-15. doi: 10.1016/j.jbspin.2014.10.008

21. Alamdari DH, GhayourMobarhan M, Tavallaie S, Parizadeh MR, Moohebati M, Ghafoori F, et al. Prooxidantantioxidant balance as a new risk factor in patients with angiographically defined coronary artery disease. Clin Biochem 2008; 41(6): 375-80. doi: 10. 1016/j.clinbiochem.2007.12.008.

22. Alamdari DH, Paletas K, Pegiou T, Sarigianni M, Befani C, Koliakos G. A novel assay for the evaluation of the prooxidantantioxidant balance, before and after antioxidant vitamin administration in type II diabetes patients. Clin Biochem 2007; 40(3-4): 248-54. doi: 10.1016/ j.clinbiochem.2006.10.017.

23. Tursen U, Gurler A, Boyvat A. Evaluation of clinical findings according to sex in 2313 Turkish 
patients with Behcet's disease. International Journal of Dermatology 2003; 42(5): 346-51. doi: $\quad 10.1046 /$ j.1365-4362.2003. 01741.x.

24. Erkilic K, Evereklioglu C, Cekmen M, Ozkiris A, Duygulu F, Dogan H. Adenosine deaminase enzyme activity is increased and negatively correlates with catalase, superoxide dismutase and glutathione peroxidase in patients with Behcet's disease: original contributions/clinical and laboratory investigations. Mediators Inflamm 2003; 12(2): 107-16. doi: 10.1080/ 0962935031000097754.

25. Alli N, Gur G, Yalcin B, Hayran M. Patient characteristics in Behçet disease: a retrospective analysis of 213 Turkish patients during 2001-4. Am J Clin Dermatol 2009; 10(6): 411-8. doi: 10.2165/11310880-00000000000000 .

26. Ozuguz P, Karabulut AA, Tulmac M, Kisa U, Kocak M, Gunduz O. Markers of endothelial dysfunction and evaluation of vascular reactivity tests in Behcet disease. Angiology 2014; 65(10): 937-43. doi: 10.1177/ 0003319713512413.
27. Şahin E, Karaman G, Uslu M, Karul A, Sendur N, Savk E. Adiponectin levels, insulin resistance and their relationship with serum levels of inflammatory cytokines in patients with Behçet's disease. J Eur Acad Dermatol Venereol 2012; 26(12): 1498-502. doi: $10.1111 / j .1468-3083.2011$. 04318.x.

28. Melikoglu M, Topkarci Z. Is there a relation between clinical disease activity and acute phase response in Behcet's disease? International Journal of Dermatology 2014; 53(2): 250-4. doi: 10.1111/ijd. 12224.

29. Jung YS, Yoon JY, Hong SP, Kim TI, Kim WH, Cheon JH. Influence of age at diagnosis and sex on clinical course and long-term prognosis of intestinal Behcet's disease. Inflamm Bowel Dis 2012; 18(6): 1064-71. doi: 10.1002/ibd. 21833.

30. Tursen U, Gurler A, Boyvat A. Evaluation of clinical findings according to sex in 2313 Turkish patients with Behcet's disease. International Journal of Dermatology 2003; 42(5): 346-51. doi: $\quad 10.1046 /$ j.1365-4362.2003. 01741.x.

31. Bozkurt M, Yuksel H, Em S,
Oktayoglu P, Yildiz M, Akdeniz $\mathrm{D}$, et al. Serum prolidase enzyme activity and oxidative status in patients with Behcet's disease. Redox Rep 2014; 19(2): 59-64. doi: $\quad 10.1179 / 1351000213 y$. 0000000072

32. Ozyazgan S, Andican G, Erman H, Tuzcu A, Uzun H, Onal B, et al. Relation of protein oxidation parameters and disease activity in patients with Behcet's disease. Clin Lab 2013; 59(7-8): 819-25. doi: $\quad 10.7754 /$ clin.lab.2012 120722

33. Harzallah O, Kerkeni A, Baati T, Mahjoub S. Oxidative stress: correlation with Behcet's disease duration, activity and severity. Eur J Intern Med 2008; 19(7): 541-7. doi: 10.1016/j.ejim.2008. 08.001.

34. Kose O. Development of immunophatogenesis strategies to treat Behcet's disease. Patholog Res Int 2012; 9: 1-7. doi: 10.1155/2012/261989.

35. Verity DH, Wallace GR, Vaughan RW, Stanford MR. Behcet's disease: From hippocrates to the third millennium. $\boldsymbol{B r} \quad \boldsymbol{J}$ Ophthalmol 2003; 87(9):1175-83. doi: 10.1136/bjo.87.9.1175. 